\title{
ABSTRAK \\ BOD DAN COD SEBAGAI PARAMETER PENCEMARAN AIR DAN BAKU MUTU AIR LIMBAH
}

\author{
Wa Atima, Prodi. Pend. Biologi Fakultas, IAIN Ambon \\ Jl. Dr. H. Tarmizi Taher, 085240517408, E-mail: wa_atima@yahoo.co.id
}

\begin{abstract}
Metode pengukuran BOD adalah mengukur kandungan oksigen terlarut awal (DO $i$ ) dari sampel segera setelah pengambilan contoh, kemudian mengukur kandungan oksigen terlarut pada sampel yang telah diinkubasi selama 5 hari pada kondisi gelap dan suhu tetap $\left(20^{\circ} \mathrm{C}\right)$ yang sering disebut dengan DO5. Selisih DO $i$ dan DO5 (DO $i$ - DO5) merupakan nilai BOD yang dinyatakan dalam miligram oksigen per liter $(\mathrm{mg} / \mathrm{L})$. Nilai BOD dapat diketahui setelah waktu inkubasi lima hari. Metode pengukuran COD adalah dengan menambahkan sejumlah tertentu kalium bikromat (K2Cr2O7) sebagai oksidator pada sampel (dengan volume diketahui) yang telah ditambahkan asam pekat dan katalis perak sulfat, kemudian dipanaskan selama beberapa waktu. Selanjutnya, kelebihan kalium bikromat ditera dengan cara titrasi. Nilai COD dapat segera diketahui setelah satu atau dua jam
\end{abstract}

Kata Kunci: BOD, COD, pencemaran air, baku mutu air limbah

\section{ABSTRACT \\ BOD AND COD AS PARAMETER OF WATER POLLUTION AND WATER QUALITY STANDARD WASTE}

The method of measurement liter is measuring the moisture content of oxygen dissolved early (DOi) of a sample of immediately after the withdrawal of example, then measuring the moisture content of oxygen dissolved in samples have been diinkubasi for 5 days in the condition of a dark and the temperature remains $\left(20{ }^{\circ} \mathrm{C}\right)$ which are often called with DO5.The difference between (DOi-DO5) are an liter expressed in oxygen milligrams per liter $(\mathrm{mg} / \mathrm{L})$. Liter value can be obtained after incubation periods five days. The method of measurement cod is by adding a certain number of potassium bichromate $\left(\mathrm{K}_{2} \mathrm{Cr}_{2} \mathrm{O}_{7}\right)$ as an oxidizer in samples (by volume known) that has been added the acid pekat and catalyst silver sulphate, then heated for some time. Next, excess potassium bichromate homer by means of a titration. COD can value immediately known after one or two hours

Keywords: BOD , cod, water pollution , quality standard waste water 
Dalam kasus-kasus pencemaran perairan, baik itu laut, sungai, danau maupun waduk, seringkali diberitakan bahwa nilai BOD dan COD perairan telah melebihi baku mutu. Atau sebaliknya, pada kasus pencemaran lainnya yang mendapat protes dari masyarakat sehubungan dengan adanya limbah industri, ditanggapi dengan dalih bahwa nilai BOD dan COD perairan masih memenuhi baku mutu. Dalam salah satu harian (Kompas edisi Senin, 12 Desember 1994) juga terdapat suatu berita dengan judul "Sebaiknya, parameter BOD dan COD tak dipakai penentu baku mutu limbah" yang kurang lebih merupakan pendapat dari salah satu pakar bioremediasi lingkungan dari Universitas Sriwijaya, Palembang. Menurut pakar tersebut, dalam banyak kasus kesimpulan yang hanya didasarkan pada hasil analisis BOD dan COD (juga $\mathrm{pH}$ ) belum merupakan jawaban ada tidaknya pencemaran lingkungan oleh suatu industri. Di sisi lain, BOD dan COD adalah parameter yang menjadi baku mutu berbagai air limbah industri selain beberapa parameter kunci lainnya. Nampaknya terdapat persepsi pada sementara kalangan yang menempatkan BOD dan COD agak berlebihan dari yang seharusnya. Sehubungan dengan hal tersebut, dalam tulisan ini akan dikaji apa itu sebenarnya BOD dan COD, bagaimana cara atau prinsip pengukurannya, dan apakah memang sebaiknya tidak dipakai sebagai penentu baku mutu air limbah.

\section{PEMBAHASAN}

\section{Pengertian BOD dan COD}

BOD atau Biochemical Oxygen

Demand adalah suatu karakteristik yang menunjukkan jumlah oksigen terlarut yang diperlukan oleh mikroorganisme (biasanya bakteri) untuk mengurai atau mendekomposisi bahan organik dalam kondisi aerobik (Umaly dan Cuvin, 1988; Metcalf \& Eddy, 1991). Ditegaskan lagi oleh Boyd (1990), bahwa bahan organik yang terdekomposisi dalam BOD adalah bahan organik yang siap terdekomposisi (readily decomposable organic matter). Mays (1996) mengartikan BOD sebagai suatu ukuran jumlah oksigen yang digunakan oleh populasi mikroba yang terkandung dalam perairan sebagai respon terhadap masuknya bahan organik yang dapat diurai. Dari pengertian ini dapat dikatakan bahwa walaupun nilai BOD menyatakan jumlah oksigen, tetapi untuk mudahnya dapat juga diartikan sebagai 
gambaran jumlah bahan organik mudah urai (biodegradable organics) yang ada di perairan. Sedangkan COD atau Chemical Oxygen Demand adalah jumlah oksigen yang diperlukan untuk mengurai seluruh bahan organik yang terkandung dalam air (Boyd, 1990). Hal ini karena bahan organik yang ada sengaja diurai secara kimia dengan menggunakan oksidator kuat kalium bikromat pada kondisi asam dan panas dengan katalisator perak sulfat (Boyd, 1990; Metcalf \& Eddy, 1991), sehingga segala macam bahan organik, baik yang mudah urai maupun yang kompleks dan sulit urai, akan teroksidasi. Dengan demikian, selisih nilai antara COD dan BOD memberikan gambaran besarnya bahan organik yang sulit urai yang ada di perairan. Bisa saja nilai BOD sama dengan COD, tetapi BOD tidak bisa lebih besar dari COD. Jadi COD menggambarkan jumlah total bahan organik yang ada.

\section{Metode pengukuran BOD dan COD}

Prinsip pengukuran BOD pada dasarnya cukup sederhana, yaitu mengukur kandungan oksigen terlarut awal (DO $i$ ) dari sampel segera setelah pengambilan contoh, kemudian mengukur kandungan oksigen terlarut pada sampel yang telah diinkubasi selama 5 hari pada Pengenceran dan/atau aerasi diperlukan

kondisi gelap dan suhu tetap $\left(20{ }^{\circ} \mathrm{C}\right)$ yang sering disebut dengan DO5. Selisih DO $i$ dan DO5 (DOi - DO5) merupakan nilai BOD yang dinyatakan dalam miligram oksigen per liter (mg/L). Pengukuran oksigen dapat dilakukan secara analitik dengan cara titrasi (metode Winkler, iodometri) atau dengan menggunakan alat yang disebut DO meter yang dilengkapi dengan probe khusus. Jadi pada prinsipnya dalam kondisi gelap, agar tidak terjadi proses fotosintesis yang menghasilkan oksigen, dan dalam suhu yang tetap selama lima hari, diharapkan hanya terjadi proses dekomposisi oleh mikroorganime, sehingga yang terjadi hanyalah penggunaan oksigen, dan oksigen tersisa ditera sebagai DO5. Yang penting diperhatikan dalam hal ini adalah mengupayakan agar masih ada oksigen tersisa pada pengamatan hari kelima sehingga DO5 tidak nol. Bila DO5 nol maka nilai BOD tidak dapat ditentukan.

Pengukuran BOD memerlukan kecermatan tertentu mengingat kondisi sampel atau perairan yang sangat bervariasi, sehingga kemungkinan diperlukan penetralan $\mathrm{pH}$, pengenceran, aerasi, atau penambahan populasi bakteri. 
agar masih cukup tersisa oksigen pada hari kelima. Secara rinci metode pengukuran BOD diuraikan dalam APHA (1989), Umaly dan Cuvin, 1988; Metcalf \& Eddy, 1991) atau referensi mengenai analisis air lainnya. Karena melibatkan mikroorganisme (bakteri) sebagai pengurai bahan organik, maka analisis BOD memang cukup memerlukan waktu. kelemahan lain BOD selain waktu Oksidasi biokimia adalah proses yang penentuan yang lama tersebut. lambat. Dalam waktu 20 hari, oksidasi bahan organik karbon mencapai 95 - 99 $\%$, dan dalam waktu 5 hari sekitar $60-70$ $\%$ bahan organik telah terdekomposisi (Metcalf \& Eddy, 1991). Lima hari inkubasi adalah kesepakatan umum dalam penentuan BOD.

Bisa saja BOD ditentukan dengan menggunakan waktu inkubasi yang berbeda, asalkan dengan menyebutkan lama waktu tersebut dalam nilai yang dilaporkan (misal BOD7, BOD10) agar tidak salah dalam interpretasi atau memperbandingkan. Temperatur $20^{\circ} \mathrm{C}$ sulfat, kemudian dipanaskan selama dalam inkubasi juga merupakan beberapa waktu. Selanjutnya, kelebihan temperatur standard. Temperatur $20^{\circ} \mathrm{C}$ kalium bikromat ditera dengan cara titrasi. adalah nilai rata-rata temperatur sungai Dengan demikian kalium bikromat yang beraliran lambat di daerah beriklim sedang terpakai untuk oksidasi bahan organik (Metcalf \& Eddy, 1991) dimana teori dalam sampel dapat dihitung dan nilai BOD ini berasal. Untuk daerah tropik COD dapat ditentukan. Kelemahannya, 
senyawa kompleks anorganik yang ada di perairan yang dapat teroksidasi juga ikut dalam reaksi (De Santo, 1978), sehingga dalam kasus-kasus tertentu nilai COD yang mudah urai (biodegradable), dan ini mungkin sedikit 'over estimate' untuk akan memberikan gambaran jumlah gambaran kandungan bahan organik. oksigen yang akan terpakai untuk Bilamana nilai BOD baru dapat diketahui dekomposisi di perairan dalam sepekan setelah waktu inkubasi lima hari, maka (lima hari) mendatang. Lalu dengan nilai COD dapat segera diketahui setelah memperbandingkan nilai BOD terhadap satu atau dua jam. Walaupun jumlah total COD juga akan diketahui seberapa besar bahan organik dapat diketahui melalui jumlah bahan-bahan organik yang lebih COD dengan waktu penentuan yang lebih persisten yang ada di perairan.

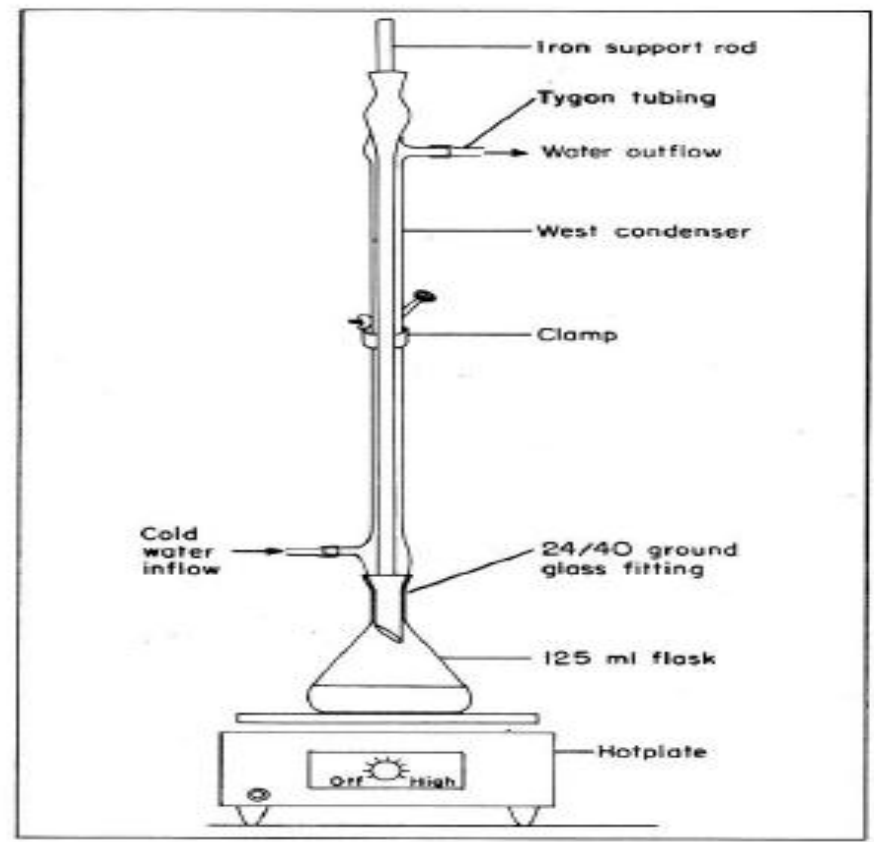

Gambar 1. Peralatan reflux untuk pengukuran COD (sumber: Boyd, 1979)

\section{Baku mutu air limbah}

Dalam rangka konservasi dalam suatu Surat Keputusan Menteri lingkungan, pemerintah telah menetapkan konsep dan pengertiannya baku mutu air baku mutu limbah cair yang dihasilkan pada sumber air yang disingkat baku mutu oleh berbagai industri dan kegiatan lainnya air, adalah batas kadar yang diperbolehkan 
bagi zat atau bahan pencemar terdapat dalam air, namun air tetap berfungsi sesuai pestisida. Dalam rangka untuk dengan peruntukannya. Baku mutu limbah melestarikan lingkungan hidup agar tetap cair adalah batas kadar yang bermanfaat bagi manusia serta makhluk diperbolehkan bagi zat atau bahan hidup lainnya perlu dilakukan pencemar untuk dibuang dari sumber pengendalian terhadap pembuangan pencemaran ke dalam air pada sumber air, limbah cair ke media lingkungan. Kegiatan sehingga tidak mengakibatkan pembuangan limbah cair oleh kawasan dilampauinya baku mutu air. Baku mutu industri mempunyai potensi menimbulkan udara ambien adalah batas kadar yang pencemaran lingkungan hidup, oleh karena diperbolehkan bagi zat atau bahan itu perlu dilakukan pengendalian. Untuk pencemar terdapat di udara, namun tidak melaksanakan pengendalian pencemaran menimbulkan gangguan terhadap makhluk air sebagaimana telah ditetapkan dalam hidup, tumbuh-tumbuhan dan atau benda. Pasal 15 Peraturan Pemerintah Nomor 20 Baku mutu air laut adalah batas atau kadar Tahun 1990 tentang Pengendalian makhluk hidup, zat, energi atau komponen Pencemaran Air, perlu ditetapkan lebih lain yang ada atau harus ada, dan zat atau lanjut Baku Mutu Limbah Cair. bahan pencemar yang ditenggang adanya Kawasan Industri adalah kawasan tempat dalam air laut. pemusatan kegiatan industri yang

Dalam

KEP-51/MENLH/10/1995 dari 21 jenis kegiatan industri, yang meliputi: industri soda kostik, pelapisan Industri logam, penyamakan kulit, minyak sawit, Perusahaan Kawasan Industri pulp dan kertas, karet, gula, tapioca, adalah perusahaan yang mengusahakan tekstil, pupuk urea, ethanol, MSG, kayu pengembangan dan/atau pengelolaan lapis, susu dan makanan dari susu, Kawasan Industri. Baku Mutu Limbah minuman ringan, industri bir,baterai Cair Kawasan Industri adalah batas kering, sabun, deterjen \& produk minyak maksimum limbah cair yang 
diperbolehkan dibuang ke lingkungan Pengolah Limbah Terpusat berlaku Baku hidup dari suatu Kawasan Industri. Mutu Limbah Cair bagi jenis-jenis industri Limbah Cair Kawasan Industri adalah sesuai dengan peraturan limbah dalam bentuk cair yang dihasilkan perundang-undangan yang berlaku. Kadar oleh kegiatan Kawasan Industri yang maksimum dari masing-masing parameter dibuang ke lingkungan hidup dan diduga atau debit limbah maksimum sebagaimana dapat menurunkan kualitas lingkungan tersebut dalam Keputusan ini dapat hidup. Mutu Limbah Cair adalah keadaan dilampaui sepanjang beban pencemaran limbah cair yang dinyatakan dengan debit, maksimum tidak dilampaui (Pasal 2). kadar dan beban pencemar. Debit Gubernur dapat menetapkan parameter maksimum adalah debit tertinggi yang tambahan di luar parameter Baku Mutu masih diperbolehkan dibuang ke Limbah Cair sebagaimana dimaksud lingkungan hidup. Kadar maksimum dalam Keputusan ini dengan persetujuan adalah kadar tertinggi yang masih Menteri (Pasal 3). Baku Mutu Limbah diperbolebkan dibuang ke lingkungan Cairnya lebih ketat atau sama dengan hidup.

Baku Mutu Limbah Cair sebagaimana

Beban pencemaran maksimum dimaksud dalam Keputusan ini dinyatakan adalah beban pencemaran tertinggi yang tetap berlaku; dan Baku Mutu Limbah masih diperbolehkan dibuang ke Cairnya lebih longgar daripada Baku Mutu lingkungan hidup. Baku Mutu Limbah Limbah Cair sebagaimana dimaksud Cair Bagi Kawasan Industri yang telah dalam Keputusan ini wajib disesuaikan mempunyai Unit Pengolah Limbah dengan Baku Mutu Limbah Cair Terpusat adalah sebagaimana tersebut sebagaimana dimaksud dalam Keputusan dalam Keputusan ini. Bagi Kawasan ini selambat-lambatnya 1 (satu) tahun Industri yang belum mempunyai Unit setelah ditetapkannya Keputusan ini

Tabel 1. Baku Mutu Limbah Cair Bagi Kawasan Industri

\begin{tabular}{|c|c|c|}
\hline Parameter & $\begin{array}{c}\text { Kadar Maksimum } \\
(\mathrm{mg} / \mathrm{liter})\end{array}$ & $\begin{array}{c}\text { Beban Pencemaran Maksimum } \\
\text { (kg/hari.Hari) }\end{array}$ \\
\hline BOD5 & 50 & 4.3 \\
\hline COD & 100 & 8.6 \\
\hline TSS & 200 & 17.2 \\
\hline pH & $6.0-9.0$ & \\
\hline
\end{tabular}


Debit limbah cair maksimum 1 L Nomor 51/2004, baku mutu BOD untuk per detik per HA lahan kawasan yang perairan bagi keperluan wisata bahari terpakai. Dengan adanya baku mutu air adalah $10 \mathrm{mg} / \mathrm{L}$, sedangkan bagi biota laut limbah, maka diperlukan baku mutu baku mutu BOD adalah $20 \mathrm{mg} / \mathrm{L}$. COD perairan, baik itu air tawar (sungai, danau, tidak termasuk parameter yang menjadi waduk, sumber air) maupun air laut. baku mutu air laut. Hal ini kemungkinan Pemerintah juga telah menetapkan baku karena penentuan COD air laut relatif agak mutu air ambient tersebut berupa sulit sehubungan dengan interferensi atau Peraturan Pemerintah (PP) RI No. 82 gangguan keberadaan klorida (Cl) yang Tahun 2001 tentang Pengelolaan Kualitas tinggi di air laut terhadap reaksi Air dan Pengendalian Pencemaran Air analitiknya.

yang didalamnya memuat baku mutu air Bila kita cermati baku mutu air tawar yang dibedakan dalam empat kelas. limbah yang ada (Tabel 1), nampak bahwa Juga telah ditetapkan baku mutu air laut walaupun BOD dan COD terpakai sebagai melalui Surat Keputusan Menteri Negara parameter baku mutu air limbah dari Lingkungan Hidup Nomor 51 Tahun 2004. hampir semua kegiatan, tetapi Didalam baku mutu air tersebut, tercakup keberadaannya adalah bersama-sama semua parameter yang digunakan dalam dengan dua atau lebih parameter lain yang baku mutu air limbah, termasuk BOD dan menjadi parameter kunci dari kualitas air COD, ditambah parameter-parameter limbah kegiatan yang bersangkutan. Ini kualitas air lainnya, termasuk parameter berarti, bukan hanya BOD dan COD yang biologi dan radio nuklida. Sebagai menjadi penentu pencemaran air limbah, ilustrasi, dalam PP Nomor 28/2001 tetapi kesemua parameter yang menjadi tersebut baku mutu BOD bagi perairan baku mutu air limbah dari kegiatan yang Kelas dua yang dipergunakan untuk bersangkutan. Dari Tabel 1 tersebut juga rekreasi air dan budidaya perikanan terlihat bahwa parameter $\mathrm{pH}$ dan TSS (akuakultur) misalnya, adalah lebih kecil (total suspended solids) misalnya, juga dari $3 \mathrm{mg} / \mathrm{L}$, sedang baku mutu COD-nya berperanan penting dalam baku mutu adalah lebih kecil dari $25 \mathrm{mg} / \mathrm{L}$. Untuk air limbah, yang lebih lanjut juga berarti laut, sebagaimana dalam Kep. MENLH berperan penting dalam penentuan tingkat 
pencemaran perairan. Dari nilai $\mathrm{pH}$ akan dapat diketahui apakah telah terjadi perubahan sifat asam-basa perairan dari nilai $\mathrm{pH}$ alaminya, bila nilainya lebih tinggi lebih dari satu unit di atas normal berarti perairan menjadi terlalu basa, sebaliknya bila terjadi penurunan maka perairan menjadi terlalu asam. Bila ini terjadi, selain mengganggu biota atau ekosistem perairan, juga akan mengurangi nilai guna air. Demikian juga TSS, bila nilainya meningkat cukup signifikan, perairan akan tampak keruh dan terkesan kotor sehingga tentu saja mengurangi daya guna airnya. Dengan demikian, bila kel misalnya nilai BOD dan COD suatu perairan masih normal atau memenuhi baku mutu, belum dapat disimpulkan bet bahwa tidak terjadi pencemaran, bila hut parameter kunci lainnya tidak diketahui. Karena bila parameter lainnya telah meningkat dan melebihi baku mutu, maka aka berarti ada indikasi pencemaran di org perairan. Hal ini dapat terjadi karena bila mengetahui ukuran fasilitas unit terdapat bahan-bahan toksik (beracun) di pengolahan limbah; (3) untuk mengukur perairan, logam berat misalnya (Mays, efisiensi suatu proses perlakuan dalam 1996; APHA, 1989), nilai BOD bisa jadi pengolahan limbah; dan (4) untuk rendah atau masih memenuhi baku mutu, mengetahui kesesuaiannya dengan batasan pada hal dalam air atau perairan tersebut yang diperbolehkan bagi pembuangan air terkandung bahan beracun atau air telah limbah. Karena nampaknya BOD akan 
tetap digunakan sampai beberapa waktu mendatang, maka penting untuk mengetahui sebanyak mungkin mengenai cara penentuannya berikut segala keterbatasan atau kelemahannya.

$$
\text { Terlepas dari berbagai }
$$

kelemahannya tersebut, BOD masih cukup relevan untuk digunakan sebagai salah satu parameter kualitas air yang penting. Karena dengan melakukan uji BOD secara apa adanya, yakni dengan tidak memperhatikan ada tidaknya kandungan bahan toksik, sedikit atau banyaknya kandungan bakteri, tetapi dengan tetap melakukan pengenceran atau aerasi bilamana diperlukan dan inkubasi pada suhu setara suhu perairan, maka akan diperoleh suatu nilai BOD yang akan memberikan gambaran kemampuan alami perairan dalam mendegradasi bahan organik yang dikandungnya. Dari nilai tersebut akan dapat dilihat apakah kemampuan perairan dalam mendegradasi bahan organik masih cukup baik atau sudah sangat rendah. Bila rendah, berarti kemampuan pulih diri (self purification) perairan sudah sangat berkurang.

\section{KESIMPULAN}

1. BOD dan COD masih diperlukan sebagai parameter dalam baku mutu air limbah atau sebagai parameter pencemaran perairan, karena peranannya sebagai penduga pencemaran bahan organik dan kaitannya dengan penurunan kandungan oksigen terlarut perairan (oksigen penting bagi kehidupan biota air dan ekosistem perairan pada umumnya). Peranan BOD dan COD bukan sebagai penentu, tetapi setara dengan parameter lainnya yang menjadi parameter kunci sehubungan dengan dugaan pencemaran oleh kegiatan tertentu.

2. BOD adalah parameter penduga jumlah oksigen yang diperlukan oleh perairan untuk mendegradasi bahan organik yang dikandungnya, sekaligus merupakan gambaran bahan organik mudah urai (biodegradable) yang ada dalam air atau perairan yang bersangkutan. Bila uji BOD dilakukan tanpa perlakuan tertentu dan dengan suhu inkubasi setara suhu perairan, maka BOD dapat menggambarkan kemampuan perairan dalam mendegradasi bahan organik. 
3. COD adalah parameter penduga jumlah total bahan organik yang ada dalam air atau perairan, baik yang mudah urai maupun yang sulit urai. Dengan memperbandingkan nilai COD dan BOD, akan diketahui gambaran jumlah bahan organik persisten (sulit urai) yang terkandung di dalamnya.

\section{DAFTAR PUSTAKA}

Apha. 1989. Standard methods for the examination of waters and wastewater. 17th ed. American Public Health Association, American Water Works Association, Water Pollution Control Federation. Washington, D.C. 1467 p.

Boyd, C.E. 1990. Water quality in ponds for aquaculture. Alabama Agricultural Experiment Station, Auburn University, Alabama. 482 p.

Boyd, C.E. 1979. Water quality in warmwater fish ponds. (4th printing, 1988). Auburn University Agricultural Experiment Station, Auburn, Alabama. p 230.

De Santo, R.S. 1978. Concepts of applied ecology. Heidelberg Science Library. Springer-Verlag, New York. 310 p.

Ekonorma. 1996. Himpunan Peraturan Perundang-undangan mengenai pengendalian dampak lingkungan EKONORMA. Edisi satu. Pusat Pengembangan Informasi dan Penaatan Lingkungan - PPIPL BAPEDAL. Yayasan Kalpawilis. Jakarta. p: 253-321. (Memuat KEP-51/MENLH/10/ 1995;
KEP-52/MENLH/10/1995;

KEP-58/MENLH/12/1995).

Harian Kompas edisi Senin, 12 Desember 1994. "Sebaiknya, parameter BOD dan COD tak dipakai penentu baku mutu limbah" (artikel).

KEP-42/MENLH/10/1996. Surat

Keputusan Menteri Negara Lingkungan Hidup Nomor KEP-42/MENLH/10/1996.

Kep. MENLH No. 112 Tahun 2003. Surat

Keputusan Menteri Negara

Lingkungan Hidup Nomor 112

Tahun 2003.

Kep. MENLH No. 113 Tahun 2003. Surat

Keputusan Menteri Negara

Lingkungan Hidup Nomor 113

Tahun 2003.

Kep. MENLH No. 51 Tahun 2004. Surat

Keputusan Menteri Negara

Lingkungan Hidup Nomor 51

Tahun 2004.

Mays, L.W.(Editor in Chief) 1996. Water resources handbook.

McGraw-Hill.New York. p: 8.27-8.28.

Metcalf \& Eddy, Inc. 1991. Wastewater Engineering: treatment, disposal, reuse.3rd ed. (Revised by: G. Tchobanoglous and F.L. Burton). McGraw-Hill,Inc. New York, Singapore. $1334 \mathrm{p}$.

Umaly, R.C. dan Ma L.A. Cuvin. 1988. Limnology: Laboratory and field guide,Physico-chemical factors, Biological factors. National Book Store,Inc. Publishers. Metro Manila. 322 p.

Peraturan Pemerintah (PP) RI No. 82 Tahun 2001 tentang Pengelolaan Kualitas Air dan Pengendalian Pencemaran Air. 